\title{
Exploring the role of environmental and ecological parameters on lithium isotope composition of marine carbonates
}

\author{
DONGYU CHEN ${ }^{1}$, FANNY THIBON ${ }^{1}$, LUCAS WEPPE ${ }^{1}$,
} AXEL FELBACQ $^{1}$ AND NATHALIE VIGIER $^{2}$

${ }^{1}$ LOV- CNRS-Sorbonne Université

${ }^{2}$ LOV - CNRS - Sorbonne Université

Presenting Author: chen.dongyu@imev-mer.fr

Lithium isotope composition of biogenic carbonates $\left(\delta^{7} \mathrm{Li}_{\text {bio }}\right)$ are one of the most promising geological archives to trace longterm changes in the global silicate weathering cycle, following the assumption that some biogenic carbonates faithfully record secular changes in seawater $\delta^{7} \mathrm{Li}$. For example, Hathorne \& James (2006) and Misra \& Froelich (2012) used the Li isotopic composition of planktonic foraminifera to reconstruct changes of seawater $\delta^{7} \mathrm{Li}$ in the Cenozoic [1-2]. Washington et al. (2020) find that fossilized brachiopods record a similar magnitude of change in seawater $\delta^{7} \mathrm{Li}$ as foraminifera [3]. These results support that biogenic carbonates are good candidates for providing a representative record of $\delta^{7} \mathrm{Li}_{\text {bio }}$ in deep time.

However, this idea has recently been challenged because $\delta^{7} \mathrm{Li}_{\text {bio }}$ may be influenced by environmental parameters. Vigier et al. (2015) and Roberts et al. (2018) demonstrated that foraminifera $\delta^{7} \mathrm{Li}$ could depend upon seawater dissolved inorganic carbon (DIC) or pH, respectively [4-5]. Dellinger et al. (2018) also reported a large range of $\delta^{7} \mathrm{Li}_{\text {bio }}$ values for various species of modern, cultured, and coretop calcifiers. These new findings suggest that $\delta^{7} \mathrm{Li}_{\text {bio }}$ could be dominantly controlled by environmental conditions or by biological / ecological parameters [6]. The present study investigates these effects by collecting all published $\delta^{7} \mathrm{Li}$ data of marine biocarbonate (foraminifera, corals, mollusks, brachiopods, echinoderms, bulk) and by developing for the first time an exhaustive statistical treatment, in particular through principal component analysis (PCA) techniques. Preliminary results allow us to explore the role of temperature and habitats, and highlight significant differences between coretop organisms compared to those cultured in the laboratory or collected in their natural environment, suggesting rapid diagenesis after deposition for several of the studied phylums.

[1] Hathorne \& James. (2006) EPSL 246, 393-406 [2] Misra \& Froelich. (2012) Science 335(6070), 818-823 [3] Washington et al. (2020) Geology 48, 1058-1061 [4] Vigier et al. (2015) C. R. Geosci. 347, 43-51 [5] Roberts et al. (2018) GCA 236, 336350 [6] Dellinger et al. (2018) GCA 236 (2018) 315-335 